\title{
Virtual Organization to Virtual Product: Structural Challenges to Online Newspapers
}

\author{
D. W. Maguire \\ Edith Cowan University, Perth, Western Australia, Australia
}

allmaguires@bigpond.com.au

\begin{abstract}
This paper is about the online newspaper industry and the organisational changes that have been necessitated by economic downturn and natural evolution. It explains how online newspapers were created as virtual organisations (VO) by publishers to protect valuable franchises and in the early stages of the technology boom were replicas of their traditional newspaper counterparts. It describes two VO structures that have applied during the online newspaper life cycle and the changes as economic pressures lead to destructuring. This has resulted in convergence of publishing cultures with online and traditional disciplines working in a multi-skilling environment on two different products with similar content delivered through physical and electronic means. A model of the new working entity is provided. The paper concludes by raising cultural organisational issues relevant to a clash of journalistic disciplines.
\end{abstract}

Keywords: virtual organisation, traditional newspapers, online publishing, media convergence, journalistic culture

\section{Introduction}

New information technology developed in the 1990s has provided in the Internet a faster, more efficient, more economic means of delivering content such as news, information, feature stories and photos than newspapers. In response to the challenge, publishers developed online entities to extend the reach of brands and maintain pre-eminence as information providers. More importantly, they had to protect valuable information franchises that had been built up through many generations.

These newspaper websites, now numbering close to 7000, were established as separate organisations, usually within newspaper offices, and were, initially, virtual newspapers, or electronic-mode copies, available to personal computer users through the worldwide web. They provided a "foot-in-the-door" as publishers, like other business sectors, set about trying to understand the phenomenon of the Internet.

These products were susceptible to the same revenue shortfall problems that led to the collapse of most Internet-based industries at the turn of the century however they have survived under the patronage of publishers who see them as an added-value extension of the traditional side of the business.

This paper discusses the organisational models through which the virtual newspaper has passed in its

Material published as part of these proceedings, either on-line or in print, is copyrighted by Informing Science. Permission to make digital or paper copy of part or all of these works for personal or classroom use is granted without fee provided that the copies are not made or distributed for profit or commercial advantage AND that copies 1) bear this notice in full and 2) give the full citation on the first page. It is permissible to abstract these works so long as credit is given. To copy in all other cases or to republish or to post on a server or to redistribute to lists requires specific permission from the publisher at publister@intormingscience.org short life and looks at workplace challenges being experienced as it is produced in a "one-newsroom, two modes" culture.

\section{Background to Research Area}

Some key thoughts relevant to the concept of the virtual organisation need to preface this paper which looks broadly at the evolving state of the 
online newspaper as it builds a significant niche in publishing. Online information is a permanent legacy of the technological revolution that has facilitated the arrival of the Information Age. Newspapers since the mid-1600s have been the principal delivery vehicle for news and information and the expertise for doing so still resides with them. The arrival of the Internet has opened up wider delivery mechanisms for the content which newspapers traditionally carried and created an opportunity for electronically enhanced products to do the same job online. The evolution of these products is continuing in the context of the following points:

Technology changes. Economic laws do not. Information technology is rushing forward, seemingly chaotically and it is difficult to discern patterns to guide business decisions. (Shapiro and Varian, 1998)

The virtual organisation is a dynamic organisational tool for agile competitors... who are seeking a strategic concept to use in an environment of change and uncertainty (Goldman et al, 1995)

The virtual newspaper is being buffeted by elements of the concepts mentioned above and is subject to a series of chaos chains that are both internal and external and driven by conflicting pressures to develop a separate culture and deal with the imperative of convergence.

\section{Protecting the Franchise}

Newspapers are collaborating with technology to put the daily news online as the electronically enabled economy facilitates better access to information and its delivery. Just as their predecessors funded start-up radio and television stations in previous generations, publishers have bought into Internet companies and formed Web businesses to protect their newspaper franchises. They publish online versions under familiar brand names to deliver news and information but while succeeding in attracting increasing numbers of users have not generated financial returns to justify the investment. The traditional printed versions are holding their strength in circulation and advertising and therefore safely delivering the returns the business model has guaranteed for decades.

If the Internet was to decimate any other medium, the newspaper was a prime candidate. Its physical format had changed only cosmetically since the invention of the printing press and the technology to this day is bound to reels of paper and electronically driven iron presses. The design is limited to the basic presentation of news and information in rows of type interspersed by pictures sitting on a base of advertisements. The pictures and graphics are static and there is no sound.

The Internet as a delivery system is all the newspaper can't be. It remains fundamentally text-based but can splash around colour and smart graphics to create visual lures. Whereas the paper needs to go to press late at night to be physically delivered in time for morning reading, the online version's content can be changed at source at will for access by users at will. Where earlier developments in a newspaper story have to be sourced back through previous days' library-stored hard copies, an online service can supply an instantly accessible electronic archive. The newspaper is purely mono-media, unable to carry soundbites or video grabs or facilitate chat lines with reporters or story subjects. Its power is that it can encourage online use through in-product pointers. Whereas businesses can't count how many newspaper readers dwell on their on-page advertisement, they can measure online advertising response by the number of "hits" recorded. The proof of advertising effectiveness in either medium is how much product is sold.

The newspaper, however, as it did through the advent of silent pictures then talkies, radio and TV, has survived the initial phase of the information economy revolution and is in splendid condition. As its online versions gain appeal and generate increased usage, the two different entities are complimenting each other and the separate cyber and non-cyber models are coming closer to convergence. Also, news flourishes on the Internet.

Pew Research Centre (2000) reported that 15 per cent of Americans log on to the Internet for news every day, compared with 6 per cent two years before; and a third of Americans read news online once a week 
compared with 20 per cent in 1998 (Anonymous, 2000). The news on the Internet has to be compiled, written and packaged by journalists who, given the youthful age of the online media concept, all had their training in traditional news-gathering environments.

\section{The Online Newspaper Model}

The concept of the virtual organisation and the mechanisms used to form it are not in themselves new (Goldman, Nagel and Priess, 1995). The unique delivery opportunities offered by the Internet, however, have compelled newspaper and other media owners to enter the e-commerce environment by forming virtual publishing organisations to issue virtual products. They have done so without a viable financial model (Maguire, 2001) and in an uncertain environment which is showing that Internet brands have been difficult to build, perhaps because the lack of physical presence and direct client contact makes virtual businesses less tangible to customers than traditional businesses (Porter, 2001)

Every major newspaper has some form of online product with many of the larger papers committing the entire product to being Web accessible. Regional, community and weekly newspapers are available online as well as most other print-original publications. It is not the first time newspapers have tried forms of electronic delivery. There have been attempts at Videotex (delivered over phone lines to home TV sets) and companies like CompuServe began offering electronic editions of national newspapers on an experimental basis in the eighties (Bittner, 1996).

There is demand for online newspaper sites and in Australia they are well established, experiencing strong growth with smh.com.au showing $200 \%$ growth in traffic and no indication that its popularity is cannibalising newspaper sales (Ryan, 2001).

The online product has evolved as a virtual newspaper in that it replicates to a large degree the content of the physical product but in an electronic environment. The network behind production of this virtual product meets the accepted criteria of a virtual organisation in that it consists of "member" organisations, in this case the contributing departments of the newspaper publishing organisation, which contribute to its content.

Lethbridge's (2001) I-based taxonomy of virtual organisations defines six basic, elemental structures for a VO, two of which are used in this paper to describe the development of online newspapers. They are:

- the Virtual Face model - a cyberspace incarnation of a non-virtual organisation, and

- the Parallel Alliance - where one member organisation adds value to the work that is being done concurrently by another virtual organisation member.

The Virtual Face model is the simplest VO structure, representing basic B2C (business-to-customer) ecommerce or e-business. In the newspaper context it offers an electronic shop front, i.e. the newspaper on the net, to its customers, reflecting all in the physical format of the hard copy version.

Burn (2001) says that rather than simply mirroring the organisation's activity, this model extends it by facilitating interactive communication with its web-based versions. In the case of publishers this involves constant news updates and archival searches. There is a tight link between the Virtual Face and the parent organisation and the existing corporate structure maintains control over what is a new communications/delivery channel for the publisher.

The development of the Virtual Face online newspaper is getting better "press" as more "old school" (i.e. traditional newspaper) journalists working in the new medium understand it better. The basic differences between the two were highlighted by McAdams (1995) who spent 16 months in the mid-1990s creating an online version of The Washington Post where a fundamental principle of the mission was that the newspaper metaphor provided a superior structural model that was easy to use. 
Virtual Organization to Virtual Product

Despite a commitment to this metaphor, McAdams concluded:

- an online service can never perfectly replicate the newspaper

- some things will always be better in the print format

- the electronic medium allows many options that are not possible on paper, and

- the demands on online staff are different from those on traditional journalists.

She found that, in many ways, the online product was not a newspaper at all but at the same time it contained the same articles as the paper. The differences were that a newspaper carried information in one direction but an online service operated in two with its users expecting involvement and response from the producers. Online allowed articles to stay available for years, it could carry large collections of data the print product couldn't afford (newsprint cost) and could be updated around the clock.

Riley et al (1998) view online communication as an opportunity to build community in virtual space and note that newspapers have been interested in the notion of building virtual communities as they move their operations online. This concept goes closer to a role the online newspaper may take in furthering public or civic journalism to cause interaction with readers on local topics than to being critical to the genesis of its future organisational structure.

The initial intent for most online off-shoots of newspapers and television appears for them to have been real Virtual Face entities that were launched, first, to protect the newspaper's existing franchise and, second, to establish a presence should the dot.com revolution amount to something. There was recognition that they would appeal to a technology-enabled audience who might consume news differently and a separate staff was hired to produce, package and enhance content for the online form. As the economy worsened in the late 1990s and recession started to reduce business and consumer spending, the labour required to sustain Virtual Face news teams, camera crews, production staff and executives could not be justified.

Print, TV and Web news companies started wholesale cutting of jobs at online news divisions in January 2001 (Wenner, 2001) because of the slump and media companies had yet to find a way to make money delivering news online. Cable News Network (CNN) was the first to signal a change of approach to its cyberspace incarnation, announcing consolidation of its multiple news-gathering operations so journalists could produce stories for radio, TV and the Internet. Fox Entertainment Group, Knight-Ridder and Tribune Co followed with a similar discipline-integrated approach that has reticulated through the industry.

This resulted in integration of responsibility for the Virtual Face organisation back into the conventional, non-virtual organisation. The cultural aspects of this will be covered later. The result has been disappearance of the Virtual Face organisation but survival of a Virtual Product and a degree of cultural virtualness being imbued almost as a necessity into the non-virtual organisation in order for the Virtual Product to retain its existence and integrity. Ultimately this could lead to a reverse takeover or back-door listing of the Virtual Face culture in the traditional environment, a concept that needs further study.

A direction has been set, therefore, to progress to an economically pragmatic new stage in the development of news online, combining technologies and resources so that Web content can be generated simultaneously with print or TV stories. The possibility rises that with the right technology and training, reporters and producers who are familiar with both media could produce packages for Web and TV within the same software interface (Palser, 2001)

This, therefore, has lead the publisher to the Parallel Alliance virtual organisation structure. In this model, one value-adding organisation works closely with another and the two are responsible for tasks that are mutually dependent. The online entity and the traditional newspaper are independent in terms of, for instance, design "look", delivery mechanisms and publishing times, things that are fundamentally uncom- 
mon according to their physiology. They cannot be integrated but they must be linked because they share the same staff, carry the same stories and pictures, operate under slight variations of the same name and promote access to each other's attributes such as archive retrieval, home delivery, stocks and shares listings and tipping competitions. The most important link is that the online entity draws an unquantifiable percentage of its users from the host product, i.e. the traditional newspaper.

\section{Progressive Changes to Virtual Newspaper Model}

Criteria of the Parallel Alliance (see Figure 1) model that are relevant to the newspaper/online entity include:

- smooth exchange of operational and co-ordination information so there is phased synchronisation when stories need updating

- customer/reader contact is by both (or all) members of the VO so that information relevant to each entity is acted upon

- the concept of a core organisation is understood to be paramount as the heart of the information gathering process

- the concept of competitive, separate delivery systems is understood to be internally healthy for the organisation.

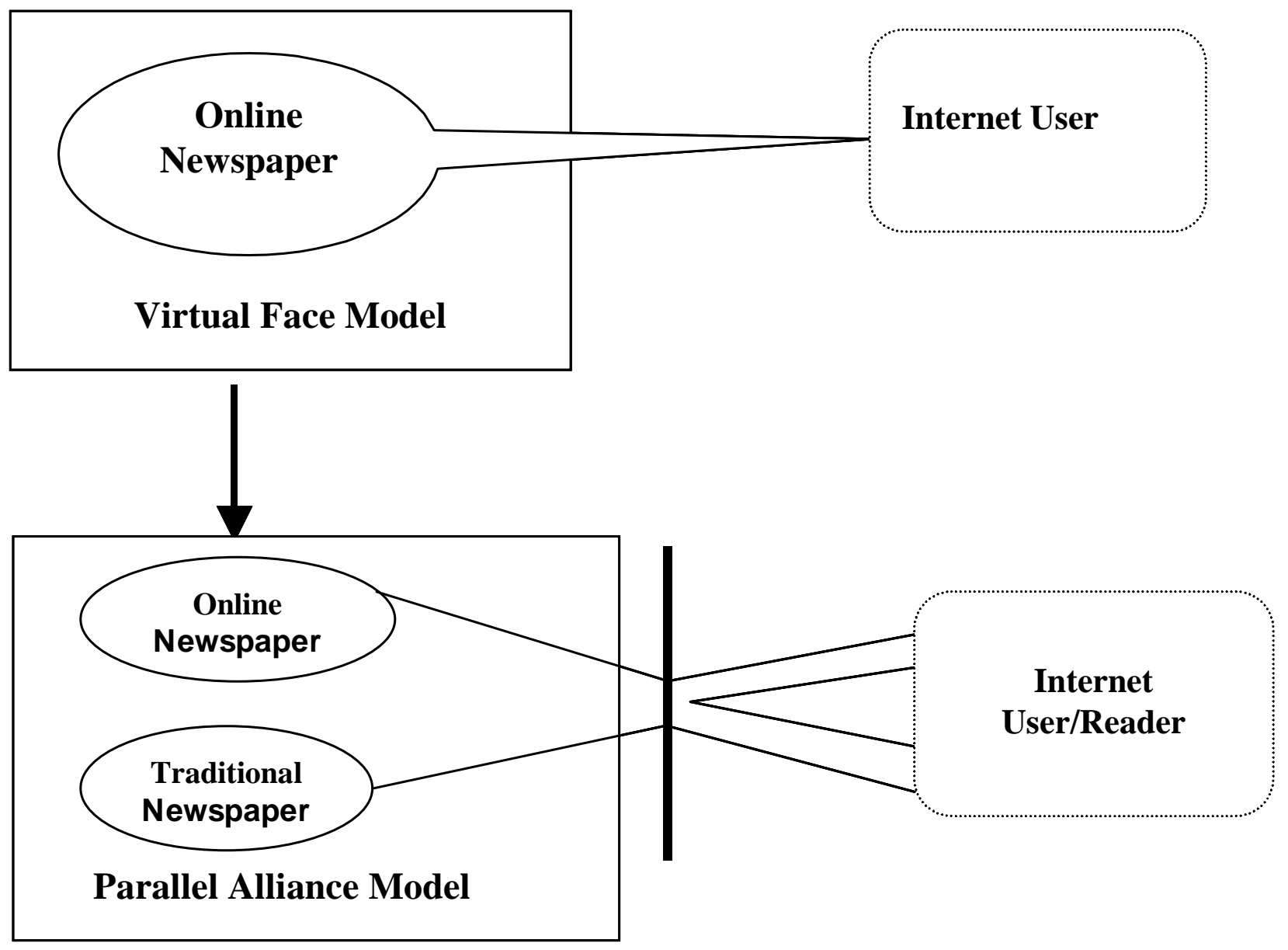

Figure 1. Parallel Alliance model (Adapted from Lethbridge, $N$ (2001)) 
Merging Virtual Face back into the traditional entity as a Parallel Alliance may be re-uniting the tail with the dog but the digital divide needs to be narrowed if an economy-driven convergence is to be successful. A valid question, though, is whether convergence is right for either new or old media.

No, believe Rayport and Sviokla (1995), who call the new information world the marketspace to distinguish it from the physical world of the marketplace and believe in mirroring capabilities and creating value in both domains but say different processes are needed for each. Boyd and Skene (1999) sound warnings about convergence of cyberspace and conventional media: web ventures will not last long trolling for content from whatever the newspaper organisation has or makes available and neither will succeed if they inhabit parallel universes. Rather than having editors managing IT-intensive projects and cajoling erratic co-operation from traditional departments, they believe organisations will need cohesive teams of people whose full understanding of the technology allows creativity in applying these tools to deliver distinctive information services. They were writing, however, prior to the application of economic imperatives in the media industry.

Their statements, however, support the findings of McAdams whose pioneering experience documented the differences and have been further confirmed as user experience banks up. Lapham (1995) noted that astute editors and publishers recognised the threat digital delivery posed to the "fourth estate" and created electronic publications to reach today's wired audiences. Many opted simply to put the content of the "paper" product online - fearing if they didn't someone else would do so and siphon away their revenues only to discover that the online world has its own, often mysterious ethos.

The case against convergence - and the trend - is further supported by Stephen Isaacs, co-chairman of the Centre for New Media at Columbia University in New York. He told Ziegler (1995) that rather than offer a new genre of multi-media presentations with video and sound and snazzy, full-motion colour graphics, most online newspapers used a deadly dull formula of scrolling text with few photos or images. This may be the pointer as to why online services aren't being stampeded by potential subscribers but the content and look of the product is in the hands of veteran newspaper people who have to make a big transition. Under convergence, they are being asked to handle content for both online and offline products, dealing with dual content cultures which adds substance to warnings made earlier in this paper.

A different approach has been taken in one American city where The Boston Globe has rethought old notions of proprietary products. Instead of just taking the newspaper online, it opened a gateway boston.com to the region with all major television stations and museums in the city joining as content partners, creating in the process a new media genre (Fulton, 1996)

\section{Cultural Clashes and Challenges}

Defining culture with Schein (1990) as shared values and beliefs, Burn together with Tushman and O'Reilly (1996) suggests that organisational cultures which are accepting of technology, highly decentralised and change oriented are more likely to embrace virtuality and actively seek these opportunities both inside and outside the organisation.

Making the transition to online has not been smooth and getting to modestly successful breakaway levels of separation has been significant but having to contract and de-structure from Virtual Face back to Virtual Product run in a Parallel Alliance will impede progress in an environment that should be oozing virtuality vitality.

Despite early concerns about quality, the Internet has become a trusted medium for delivery of news and mainstream print and television organisations have made it an important part of their distribution systems. Whether a journalist works for traditional or online media or in a hybrid of both cultures, the profession has coped with the rapid emergence of the new medium. Kansas (2001) said the Internet behaved as an open market and readers quickly discovered that it provided ample space for quality. 
A number of studies have been done on the transition between the traditional and online cultures on various aspects of publishing.

McAdams found the journalistic culture was not suited to interactivity, with most reporters interested in telling the world what was going on and creating a compelling account of events. A journalist with little online experience tended to think in terms of stories, news value, public service and things that are good to read. A person with a lot of online publishing experience thought more about connection, organisation, movement within and among sets of information and communication among different people online. Most (newspaper) reporters were horrified at the idea that readers would send them e-mail about a story they wrote and might even expect an answer (Riley et al, 1998)

The key to understanding the online newspaper organisations that are providing users with up-to-theminute reporting is the increasing stress related to instantaneous reporting (Gillmor, 1997). While various reporters hail the opportunity to crossover from a newspaper to what is perceived to be the more immediate online medium (Napoli 1999; Kansas 2001), there are warning voices about the speed at which it supplies information. Kansas notes print journalists involved with Internet distribution must learn to fuse their traditional "mulling and debating" strengths with the skill of real-time decision making to take advantage of the medium's ability to offer a quick first draft of print journalism.

Cybermedia students believed the stale brand of news being served by the online genre would prevent it becoming a dominant provider of local news and information (Lasica, 2001). If consumers can't find breaking news from their online paper they'll go elsewhere to a television or alternative "channel" for their needs. Palser (2001) says Web editors know that a news story must be repackaged and constantly updated in order to be any good online and that immediacy, depth and interactivity should never be compromised.

The real beauty of the new technology is its ability to enable newspapers to not only enhance their researching and reporting capabilities, but also to deliver a better, more audience-aware product in an immediate and inexpensive way (Lapham, 1995). The Internet has caused democratisation of information and provided newspaper businesses with an alternative delivery method for their text-based information. As the Information Age progresses and there is more media convergence, online and offline services will develop more tailored news packaging with enhanced depth and timeliness to suit the needs of their separate customer bases.

\section{Conclusion}

The online virtual product developed by newspapers to extend their reach into Internet-enabled markets will survive the pressures of economic constriction however the virtual organisations which nurtured and developed them may not. The Virtual Face model fits the characteristics of a virtual organisation such as a newspaper but is shown susceptible to being discarded in times of necessity such as economy-driven restructure. As both the online and offline cultures of publishing are merged across the spectrum of newspapers, radio and television, the practitioners paid to collect and package information for the different streams will be challenged to maximise the potential of either system.

\section{References}

Anonymous (2000). The Failure of New Media, The Economist, London, 19/8/2000, pp. 59-62

Barring, F (2001). Rethinking Internet News as a Business Proposition, The New York Times on the Web, 22 January, WWW.nytimes.com/2001/01/22/technology/22PAPE.htm/

Bittner, J (1996) Mass Communication $\left(6^{\text {th }}\right.$ Ed). Allyn \& Bacon, Needham Heights, Massachusetts, USA

Boyd, W and Skene, N (1999) Analysts: Reorganisation for Web Doesn't Guarantee Online Success, The Digital Edge,

http:T/www.digitaledge.org/monthly/1999_07/Vianage.htm! 
Virtual Organization to Virtual Product

Burn, J. M (2001) e-Business Models for Virtual Organisations, School of Management Information Systems, Edith Cowan University. Perth, WA

Fulton, K (1996) A Tour of Our Uncertain Future, Columbia Journalism Review, March/April. hittp://www.cjr.org/year/96/2/tour.asp

Goldman, S. L., Nagel, R. N. and Preiss, K (1995) Agile Competitors and Virtual Organisations: Strategies for Enriching the Customer, Van Nostrand Reinhold, New York, USA

Gillmour, D. (1997, April) The Online Newsroom, Presentation at the Freedom Forum Technology Conference, San Francisco, USA

Kansas, D (2001), Online Journalism Comes of Age, The New York Times, Technology Section, New Economy, July 16, http://www.nytimes.com/2001/07/16/technology/ebusiness/16NECO.htm/

Lapham, C (1995) The Evolution of the Newspaper of the Future, CMC Magazine, July, http://www.ibiblio.org/cmc/mag/1995/ju//tapham.hm!

Lasica, J. D. (2001) Time to Freshen up Online Newspapers, American Journalism Review AJR Newslink, July 3-9, http:/ajr.newslink.org/ajriasica697.htm

Lethbridge, N (2001) An I-Based Taxonomy of Virtual Organisations and the Implications for Effective Management, Informing Science: Developing Effective Organisations, Volume 4, No 1, 2001

Maguire, D (2001) Making Sense of Online Publishing, $6^{\text {th }}$ APDSI Conference, Singapore

McAdams, M (1995) Inventing an Online Newspaper, Interpersonal Computing and Technology: An Electronic Journal for the $21^{\text {st }}$ Century, Vol. 3, No 3, pp64-90

Napoli, L (1999), Path from Old Media to New Becomes More Crowded, The New York Times on the Web, May 18, hittp://www.nytimes.com/1ibrary/tech/99/05/cyber/articles/18media.htmp

Palser, B (2001) Retooling Online News, American Journalism Review AJR Newslink, March. http://ajr.newslink.org/ajrbarbmarot.htm

Palser, B (2001) Brave Old World, American Journalism Review AJR Newslink, July/August. http://ajr.newslink.org/ajrbarbjulo1.htm

Pew Research Centre (2000) For the People and the Press, www.people-press.org/techoosum.htm

Porter, M. E (2001) Strategy and the Internet, Harvard Business Review, March, pp. 63-78

Rayport, J. F and Sviokla, J. J (1996) Exploiting the Virtual Value Chain, The McKinsey Quarterly, No 1, pp. 20-37

Riley, P; Keough, C.M; Christiansen, T; Meilich, O; and Pierson, J (1998) Community or Colony: The Case of Online Newspapers and the Web, University of Southern California, USA. www.ascusc.org/]cmc/vo/4/1Ssue I/keough.htmI

Ryan, R (2001), Real Demand for Virtual Newspapers, B\&T Marketing and Media, Reed Business Information, Sydney. http://www.bandt.com.au/articles/as/0c002eas,asp

Shapiro, C, and Varian, H. R. (1998) Information Rules: a Strategic Guide to the Network Economy, Harvard Business School Press, Boston, USA

Schein, E (1990) Organisational Culture, American Psychologist, Vol. 45, No 2, pp 109-119

Tushman, M. L. and O’Reilly, III, C. A. (1996) Ambidextrous Organisation: Managing Evolutionary and Revolutionary Change, California Management Review, Vol. 38, No 4, pp. 8-29

Wenner, K. S (2001) Downsized Dotcoms, American Journalism Review AJR Newslink, March, http://ajr.newslink.org/ajrkathymarol.htm

Ziegler, B (1995), Stop the Presses: Publishers Scramble into Online Services, but Payoff is Unclear, The Wall Street Journal, April 26, p 1

\section{Biography}

D. W. Maguire is in postgraduate studies for a Doctor of Business Administration (Information Systems) at Edith Cowan University in Perth, Western Australia. He has been a journalist and administrator in newspapers for 30 years. 